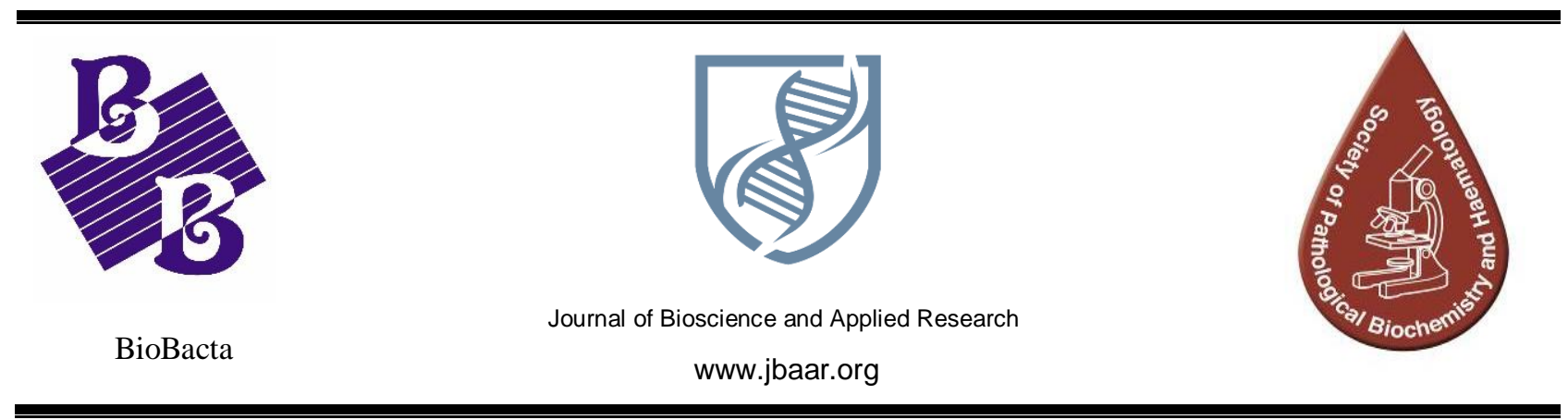

\title{
Impact of Selenium Compared to Thiotacid Supplementation on Fatigue Score in Hemodialysis Patients
}

\section{Zeinab Al Kasaby', Mohamed Abdel Latif ${ }^{2}$, Magdy ElSharkawy ${ }^{3}$, Maha Abd Elrhman ${ }^{4}$, Hosny A. Elewa ${ }^{5}$}

1- Assistant Professor and Head of Clinical Pharmacy Department, Faculty of Pharmacy (Girls), Al-Azhar University (zeinabalkasaby.pharmg@azhar.edu.eg) Corresponding author

2- Professor and Head of Clinical Pharmacy Department, Faculty of Pharmacy, Assuit University (abdellmm77@gmail.com)

3- Professor of Nephrology, Faculty of Medicine, Ain Shams University (magdi35@hotmail.com)

4- Master degree in pharmaceutical science, Faculty of Pharmacy (Girls), Al-Azhar University

(Maha.AbdelRahman@azhar.edu.eg)

5- Assistant Professor and Head of Pharmacy Practice Department, Horus University.

(hosnyelewa1960@yahoo.com)

Received: March 31, 2020. Accepted: April 15, 2020. Published: April 20, 2020.

\begin{abstract}
Background: Hemodialysis patients (HD) always suffer from fatigue, which is associated with poor healthrelated quality of life (HRQoL) in this population. Purpose: To evaluate the intensities of fatigue in HD patients, we evaluated the impact of selenium and thiotacid on their fatigue level and the reflection of their antioxidant effect on HRQoL. Methods: This study was a prospective, randomized controlled clinical trial. It was carried out in two dialysis units of Ain Shams University Hospitals. The study protocol was approved by the Research Ethics Committee (REC), Faculty of Medicine, Ain Shams University, No. (FMASU MD, 381/2018). Informed consent was obtained from all individual participants included in the study. Between August 2018 and January 2019, HD patients who completed the Arabic Translated form of the Fatigue Severity Scale (FSS). FSS was assessed at baseline and three months after starting therapy with selenium or thiotacid. Results: All HD patients were suffering from severe fatigue states (mean fatigue scores of 6.04, 6.09, and 6.115) for the control, selenium, and thiotacid groups, respectively. After three months, the mean fatigue score elevated from 6.04 to 6.518 in the control group. Supplementation with selenium and thiotacid positively affected the reduction of fatigue score by $46.5 \%$ and $44.19 \%$ in selenium and thiotacid groups, respectively. There was no significant difference between the two drugs in the improvement of fatigue state in both treated groups. Conclusion: Selenium or thiotacid supplementations successfully decreased fatigue in HD patients.
\end{abstract}

Keywords: Fatigue, Selenium, Thiotacid, Hemodialysis, Fatigue Severity Scale

DOI: 10.21608/jbaar.2020.116132 


\section{Introduction:}

Chronic fatigue is a widespread symptom, with a prevalence of approximately $10 \%$ to $15 \%$ in the general population worldwide [1]. Fatigue is one of the most common complications in hemodialysis patients, which significantly affects the quality of life of these patients [2].

It is a multifarious, multidimensional, and multifactorial phenomenon, which has been defined as 'extreme and insistent tiredness, weakness, or exhaustion- mental, physical, or both [3].

Collective symptoms of fatigue are reduced motivation, physical activity, and broad lethargy. HD patients adjust the timing and intensity of their daily activities to accommodate their fatigue [4]. For example, particular dialysis patients who suffer from post-treatment fatigue require more than $3 \mathrm{~h}$ of rest after each session to recover, while other patients need bed rest for two days until the time of the second session, which is a substantial burden on top of the treatment regimen. On the other hand, fatigue symptoms are associated with all-cause and cardiacrelated mortality in HD patients, which is considered one of the most risk associated consequences of fatigue, so the executive of fatigue is important clinical importance for enhancing the patients' QoL [5].

The causes of fatigue in HD patients are still muddled. Loss of skeletal muscle strength helps in fatigability due to the loss of muscle fibers and atrophy of the remaining fibers. It is accelerated by oxidative stress, which promotes catabolic state and muscle atrophy [6]. Other factors play an important role in HD patients' fatigue as the HD procedure itself, and the duration of the session. It was found that thirty-three \% (33\%) of HD patients felt bad in the first few hours immediately after the HD session. Also, one in four indicated severe to very severe fatigue levels after the HD session [2]. Several studies have suggested a link between oxidative stress and chronic fatigue and reported that there is a correlation between fatigue symptoms and blood levels of oxidative stress biomarkers, such as malondialdehyde and isoprostane $[\mathbf{7 , 8}]$. Thus, the reduction of oxidative stress may improve the clinical fatigue situation of these patients and thus improve their quality of life.
Assessment tools of fatigue are generally self-report measures, which evaluate, assess the fatigue severity, or discriminate the purpose of difference between fatigued and non-fatigued individuals [9]. When choosing a fatigue assessment tool, it is important to consider the aspect fatigue that is studied (i.e, unidimensional/multidimensional measure), the psychometric properties of the measure, and the population intended in the study [5]. FSS is one of the most commonly used scales for assessing fatigue in renal patients, as it has psychometric properties that are corroborated by several studies in multiple diseases, such as fibromyalgia, multiple sclerosis, chronic hepatitis, and Parkinson's disease [10]. Also, FSS has been shown to have respectable consistency and a high internal constancy so it was selected to be used in this study.

\section{Patients, Materials, and Methods}

This study was an open-label, parallel, randomized, prospective, controlled study, all HD patients (212) from 2 dialysis units in El Demirdash Hospital, one of Ain Shams University Hospitals, Nephrology Department. Were asked to take part in this study. Only 68 out of 212 HD patients were eligible for the study according to the inclusion criteria (clinically stable patients on hemodialysis for at least 3 months, aged between 18 and 60 years old, both sexes, ability to write and read Arabic language fluently), and free from exclusion criteria (patients suffering from other diseases, which may lead to oxidative stress, such as inflammatory diseases, SLE, hepatic or respiratory diseases, smokers and alcoholics, and non-compliant patients who did not adhere to the therapy during the period of study). All participants gave their written informed consent.

The fatigue level of all participants was assessed at baseline, and then they were stratified by a simple randomization method using the Research Randomizer online program, into three groups of a control group, which included 25 patients. The selenium group included 23 patients who were treated with $200 \mu \mathrm{g}$ selenium, once daily, and the thiotacid group included 20 patients who were treated with $600 \mathrm{mg}$ thiotacid once daily.

Latterly of the study, the patient's discernment of fatigue was evaluated using the nine items on the 
Fatigue Severity Scale (FSS). The FSS includes nine items grouped into six domains: 1) motivation, 2) exercise, 3) physical functioning (two items), 4) duties and responsibilities, 5) social life, and 6 ) subjective perception of fatigue (three items). FSS scores varied from one to seven, with lower scores indicating less fatigue. This means that the minimum possible score is nine, and the highest is 63 . Another way of scoring by calculating the mean of all scores (Sum scores /9) so the minimum score was 1 and the maximum score was 9 . The higher the score, the more severe the fatigue, and the more it affects the person's activities. For the statistical analysis, SPSS Statistics version 20 was used.

\section{Results:}

Of the 68 patients, 60 completed both questionnaires, including 22 patients in the control group (C gp.), 20 patients in the selenium group (S gp.), and 18 patients in the thiotacid group (T gp.).

A total of 8 patients did not complete the study due to death of three patients from the control group, while in the selenium group; there were two patients underwent renal transplantation, and one patient was transferred to a private HD center, and two patients were dropped out from the thiotacid group as they were noncompliance patients before completing the study as shown in (Figure 1).

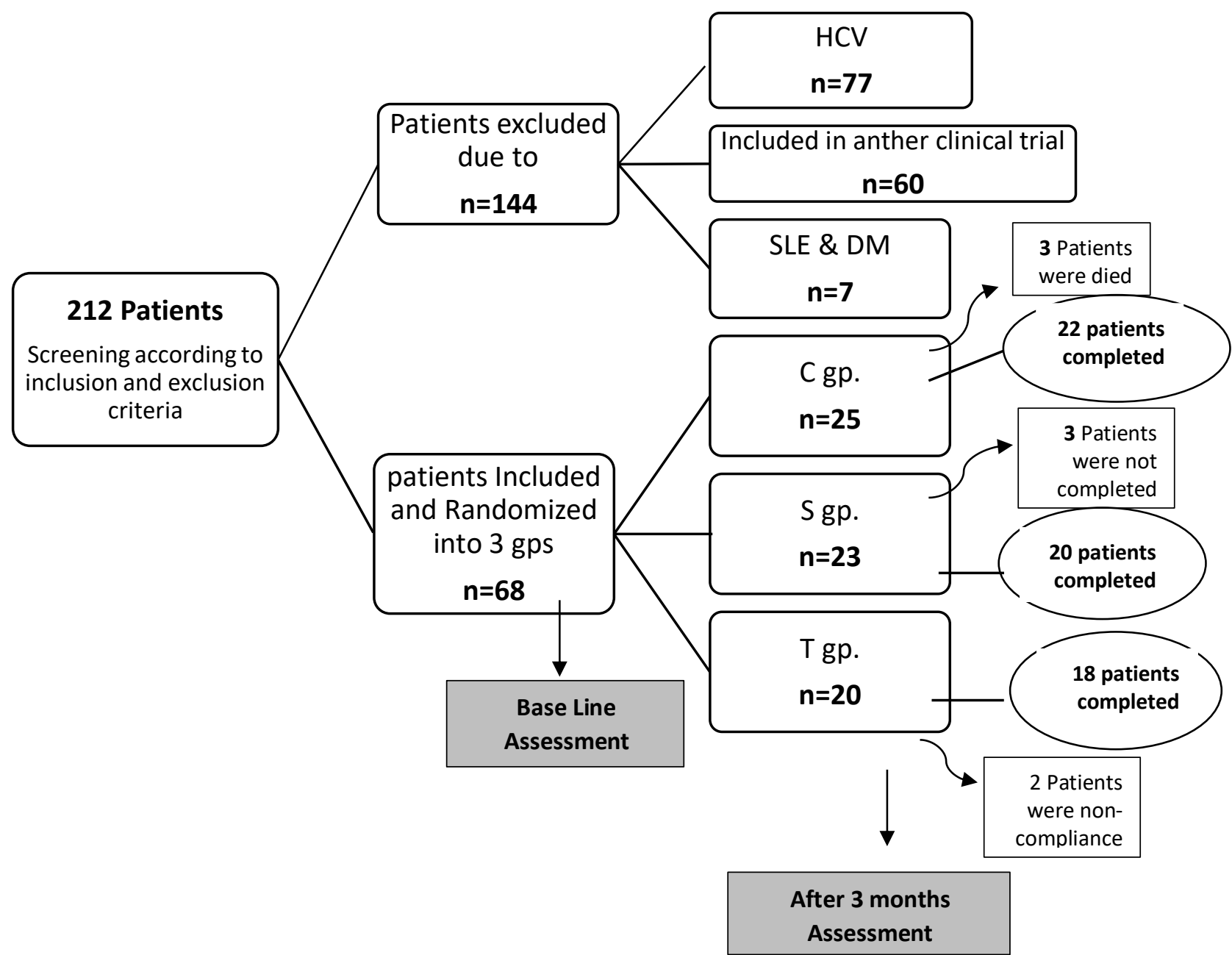

Figure (1): Flow diagram representaion of the study design

$\mathbf{N}$, number of patients; S, selenium; T, thiotacid; C, control, SLE, systemic lupus erythematous; DM, diabetes mellitus.

All groups were matched at the baseline assessment. The assessment of fatigue state for all patients at baseline using FSS showed that all HD patients suffered from severe fatigue state (mean fatigue score was 6.04, 6.09, and 6.115) for the control, selenium, and thiotacid groups, respectively. There was no significant difference between the three study groups, as illustrated in Table (1) and figure 2). 
Table (1): Assessment of fatigue using FSS for study groups at baseline

\begin{tabular}{|c|c|c|c|c|c|}
\hline \multirow{2}{*}{$\begin{array}{l}\text { Fatigue Score } \\
\text { at base line }\end{array}$} & \multicolumn{3}{|l|}{ Groups } & \multirow[t]{2}{*}{ P value } & \multirow[t]{2}{*}{ Significant } \\
\hline & $\begin{array}{l}\text { Control } \\
\text { group } \\
(\mathrm{N}=22)\end{array}$ & $\begin{array}{l}\text { Selenium } \\
\text { group. }(\mathrm{N}=\mathbf{2 0})\end{array}$ & $\begin{array}{l}\text { Thiotacid } \\
\text { group }(\mathrm{N}=\mathbf{1 8})\end{array}$ & & \\
\hline \multirow[t]{3}{*}{ Mean \pm SD } & $6.04 \pm 0.758$ & $6.095 \pm 0.623$ & & 0.968 & No \\
\hline & $6.04 \pm 0.758$ & & $6.115 \pm 0.793$ & 0.941 & No \\
\hline & & $6.095 \pm 0.623$ & $6.115 \pm 0.793$ & 0.996 & No \\
\hline
\end{tabular}

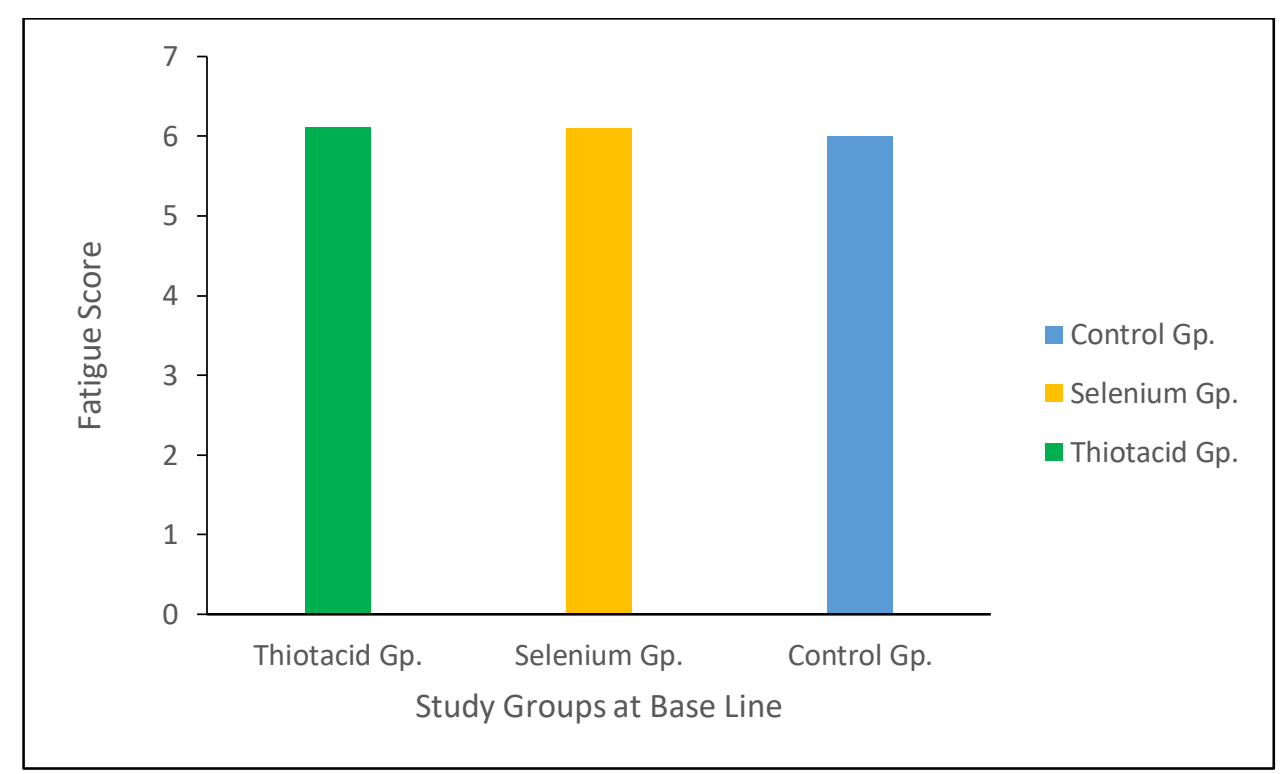

Figure (2): Assessment of fatigue using FSS for study groups at baseline

After patients' randomization into three groups, the treatment by selenium and thiotacid were started for the selenium and thiotacid groups, respectively, for three months.

After three months, the FSS was repeated for all patients. In the control group, the mean fatigue score was 6.04 at baseline and elevated to 6.518 after three months, which indicates further deterioration of those patients, as shown in Table (2) and figure 3). 
Table (2): Assessment of fatigue using FSS for the control group at baseline and after Three months

\begin{tabular}{|l|l|l|l|l|}
\hline \multirow{2}{*}{ Fatigue Score } & \multicolumn{2}{|c|}{ Control Group $(\mathrm{N}=22)$} & \multirow{2}{*}{ P value } & \\
\cline { 2 - 3 } & at base line & After 3 months & & \\
\hline Mean \pm SD & $6.04 \pm 0.758$ & $6.518 \pm 0.653$ & $<0.0001$ & $\begin{array}{l}\text { Yes } \\
* * *\end{array}$ \\
\hline
\end{tabular}

$* * *: P<0.05$

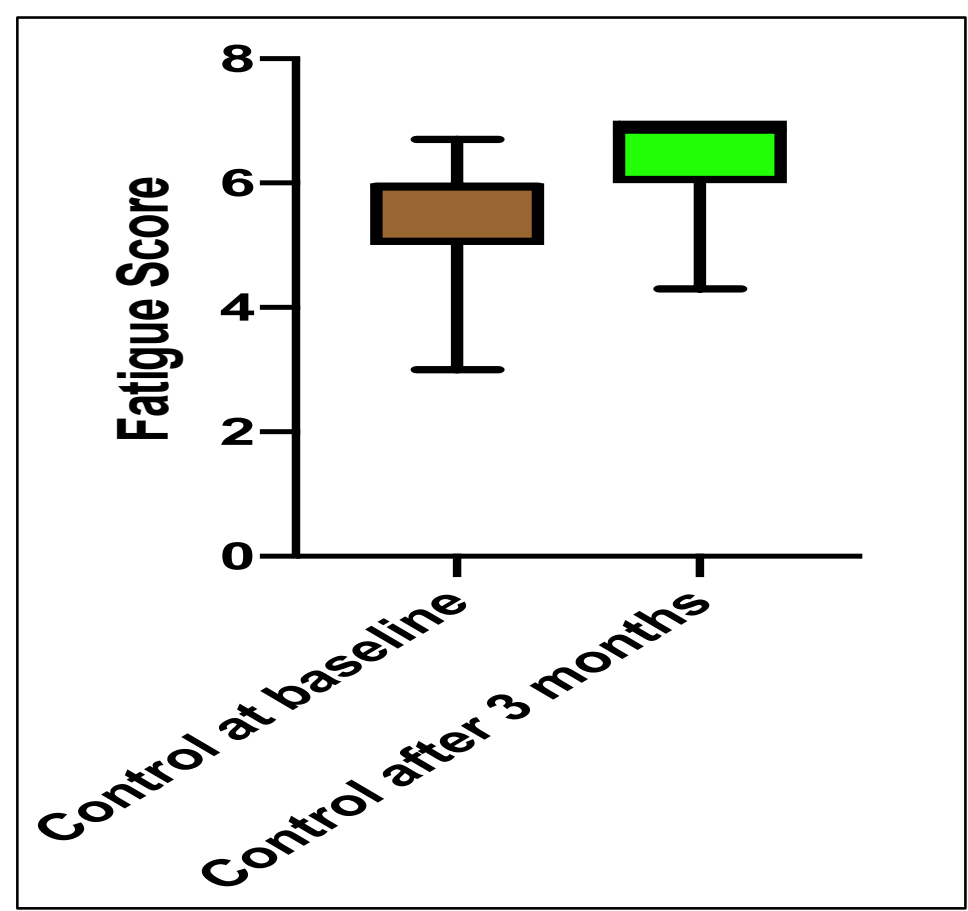

Figure (3): Assessment of fatigue using FSS for the control group at baseline and after Three months

Table (3) and figure 4) illustrate the effect of selenium on the fatigue state in HD patients, where there was a highly significant difference in the mean fatigue score $(p$ value $<0.0001)$ at baseline and after three months from the start of the treatment, as the mean fatigue score decreased by 2.835 . 
Table (3): Assessment of fatigue using FSS for the selenium group at baseline and after Three months:

\begin{tabular}{|l|l|l|l|r|}
\hline \multirow{2}{*}{$\begin{array}{l}\text { Fatigue } \\
\text { Score }\end{array}$} & \multicolumn{2}{|l|}{ Selenium Group (N=20) } & \multirow{2}{*}{ P value } & \\
\cline { 2 - 4 } & at base line & After 3 months & & \\
\hline Mean \pm SD & $\mathbf{6 . 0 9 5} \pm \mathbf{0 . 6 2 3}$ & $3.26 \pm 0.518$ & $<0.0001$ & \\
& & & & Yes \\
\hline
\end{tabular}

$* * *: P<0.05$

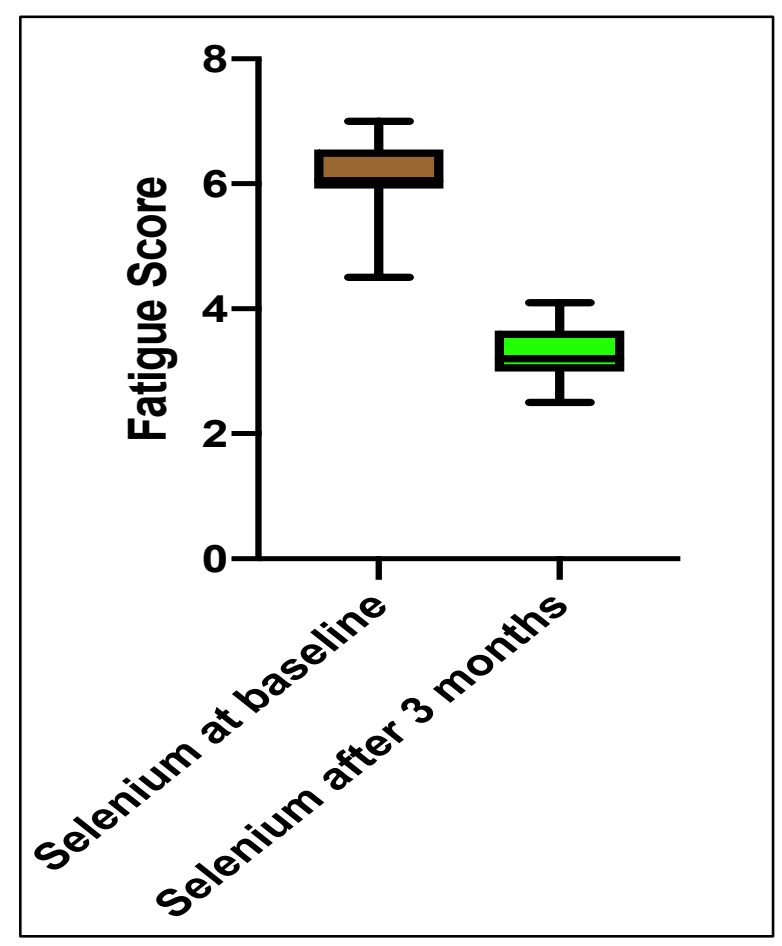

Figure (4): Assessment of fatigue using FSS for the selenium group at baseline and after Three months Also, thiotacid showed the same effect on fatigue state as the mean fatigue score decreased from 6.115 to 3.4125 after three months of therapy, as shown in Table (4) and figure 5). 
Table (4): Assessment of fatigue using FSS for the thiotacid group at baseline and after Three months

\begin{tabular}{|l|l|l|l|r|}
\hline \multirow{2}{*}{$\begin{array}{l}\text { Fatigue } \\
\text { Score }\end{array}$} & \multicolumn{2}{|l|}{ Thiotacid Group $(\mathrm{N}=18)$} & \multirow{2}{*}{ P value } & \\
\cline { 2 - 5 } & at base line & After 3 months & & \\
& & & & \\
\hline Mean \pm SD & $6.115 \pm 0.793$ & $3.4125 \pm 1.051$ & $<0.0001$ & $* * *$ \\
\hline
\end{tabular}

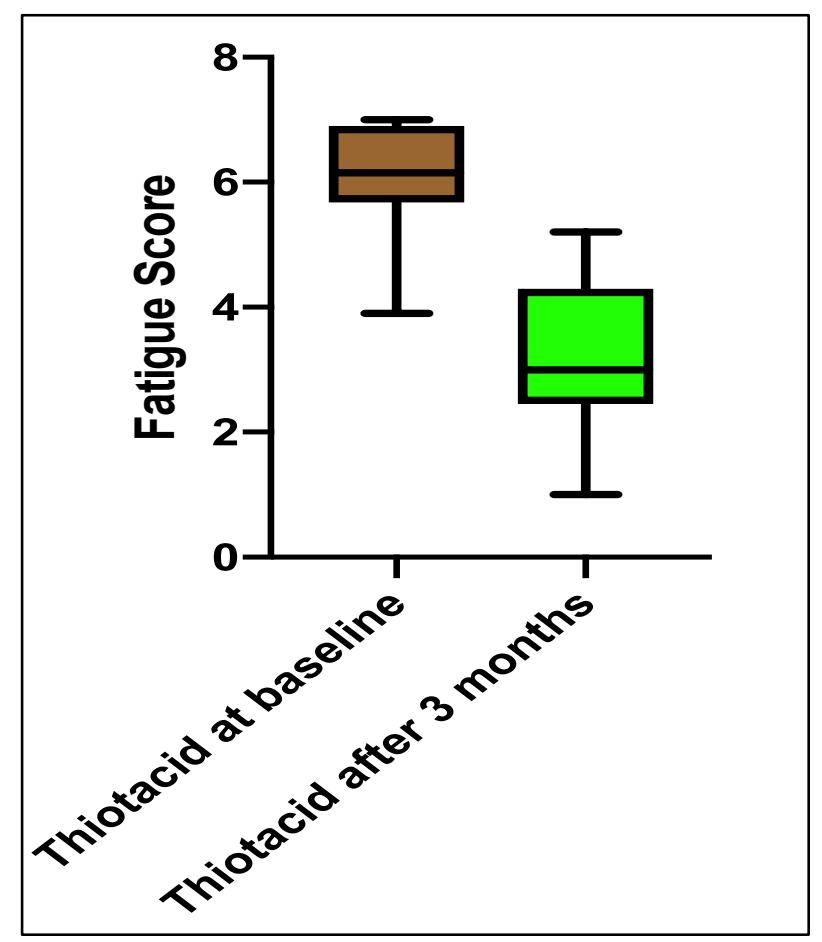

Figure (5): Assessment of fatigue using FSS for the thiotacid group at baseline and after Three months

The results explained the significant effect of both drugs on fatigue state in HD patients in comparison with the absence of antioxidant therapy, as in the control group. On the other hand, we found that there was no significant difference between the two drugs in the improvement of fatigue state in both treated groups, as the mean score in the selenium group was 3.26, while that of the thiotacid group was 3.4125 , as illustrated in Table (5) and figure (6). 
Table (5): Assessment of fatigue using FSS for study groups after 3 months

\begin{tabular}{|c|c|c|c|c|c|}
\hline \multirow{2}{*}{$\begin{array}{l}\text { Fatigue } \\
\text { Score } \\
\text { after } 3 \\
\text { months }\end{array}$} & \multicolumn{3}{|l|}{ Groups } & \multirow[t]{2}{*}{ P value } & \multirow[t]{2}{*}{ Significant } \\
\hline & $\begin{array}{l}\text { Control group } \\
(\mathrm{N}=22)\end{array}$ & $\begin{array}{l}\text { Selenium group. } \\
(\mathrm{N}=20)\end{array}$ & $\begin{array}{l}\text { Thiotacid } \\
\text { group }(\mathrm{N}=\mathbf{1 8})\end{array}$ & & \\
\hline \multirow[t]{3}{*}{$\begin{array}{l}\text { Mean } \pm \\
\text { SD }\end{array}$} & $6.518 \pm 0.653$ & $3.26 \pm 0.518$ & & $<.001$ & Yes \\
\hline & $6.518 \pm 0.653$ & & $3.4125 \pm 1.051$ & $<.001$ & Yes \\
\hline & & $3.26 \pm 0.518$ & $3.4125 \pm 1.051$ & 0.993 & No \\
\hline
\end{tabular}

$* * *: P<0.05$

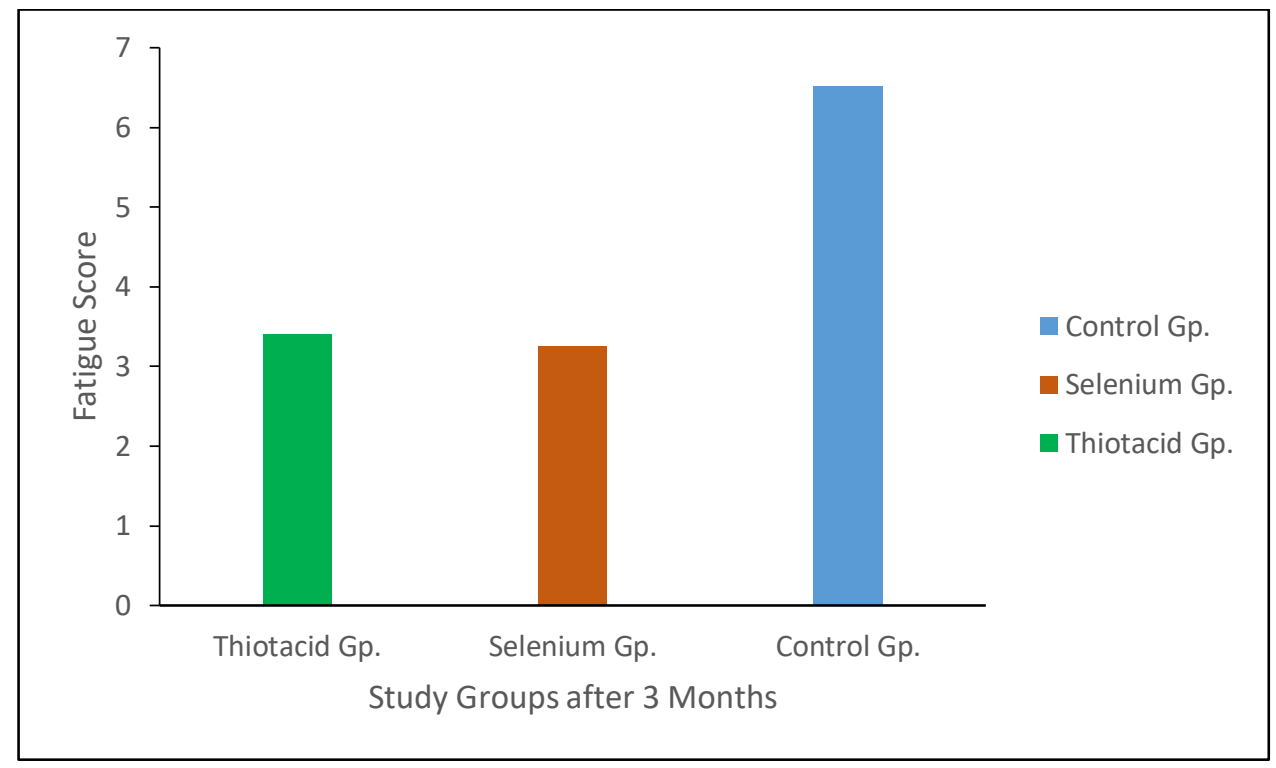

Figure (6): Assessment of fatigue using FSS for study groups after 3 months

\section{Discussion:}

Fatigue lesser the feeling of being well in dialysis patients and has several effects on their physical, emotional, and cognitive features [11]. In this study, there was significant variance between the fatigue score in the study groups before and after the intervention, which was due to the antioxidant effect of selenium and thiotacid for three months.

The sources of fatigue in hemodialysis patients are unknown, and the management of this provoking condition is necessarily difficult. [12]. Inappropriately, studies that have assessed therapeutic policies to inhibit or diminish fatigue in dialysis patients are few, generally included a small population sample, and were not randomized and controlled. In previous studies, patients can be divided into two groups: pharmacological and nonpharmacological interventions. In addition, recent data suggest that nephrologists may not be aware of many of the symptoms that disturb dialysis patients and the shortages in the applicable treatment 
of their symptoms [13]. So in this study, we tried to overwhelm the previous weaknesses. This study was a randomized trial with a control group of HD patients, with pharmacological intervention in both treated groups in comparison with the untreated control group. Besides the comparison between the therapeutic effect of two antioxidants (selenium and thiotacid) on fatigue score.

Many studies have tested the effect of 1-carnitine supplementation on fatigue and post-dialysis fatigue in a brass study [14]. But their results showed that the data remain conflicting and inconclusive. Also, Singer's study on Vitamin C, which was at low serum levels in HD patients (Singer, et al., 2007), which was a 3-months, double-blind, randomized trial of vitamin C (250 mg/day) or matching placebo given thrice weekly miscarried to prove that ascorbic acid supplementation recovers fatigue and other symptoms evaluated by the Kidney Quality of Life Short Form version (KDQOL-SF) symptom subscale [15].

Overall, it seems that none of the tested drugs can be recommended for the prevention and treatment of fatigue in chronic HD patients.

Therefore, our study considers the first and unique study reached to positive pharmacological effects of antioxidants on fatigue symptoms.

Many previous studies have concluded that selenium is an effective supplement for alleviating oxidative stress and inflammation by the assessment of many oxidative stress biomarkers in patients on hemodialysis, as the study by Salehi et al. [16, 17]. Also, thiotacid supplementation proved its activity shown to reduction of oxidative stress biomarkers in HD patients in many studies $[\mathbf{1 8 ,} \mathbf{1 9}]$.

Overall, these studies assessed the antioxidant effect of selenium and thiotacid by biomarkers only, and they did not study the drugs effect on the clinical outcomes and patient's quality of life.
In our study, we focused on the therapeutic effect of these antioxidant supplementations on clinical outcomes by assessing the fatigue score.

Our study had some limitations. First, we did not compare the fatigue scores of HD patients with healthy volunteers. Second, we conducted this study in a single center with a small number of patients. Further multicenter clinical trials are required to determine the exact effect of $\mathrm{Se}$ and thiotacid supplementation on the fatigue score of HD patients.

\section{Conclusion:}

Based on the above, we conclude that the administration of selenium and thiotacid has been used successfully to relieve fatigue in patients undergoing hemodialysis, and will reflect positively in the improvement of their quality of life.

\section{References:}

1. Wong WS, Fielding R. Prevalence of chronic fatigue among Chinese adults in Hong Kong: a population-based study. $\mathbf{J}$ Affect Disord. 2010;127:248-56. doi: 10.1016/j.jad.2010.04.029.

2. Sofia Zyga, Victoria Alikari, Athanasios Sachlas, Evangelos C. Fradelos, John Stathoulis, Georgios Panoutsopoulos, Maria Georgopoulou, Paraskeui Theophilou, and Maria Lavdaniti. Assessment of Fatigue in End Stage Renal Disease Patients Undergoing Hemodialysis: Prevalence and Associated Factors. Med Arch. 2015 Dec; 69(6): 376-380.

3. Victoria Alikari, Athanasios Sachlas, Stavroula Giatrakou, John Stathoulis, Evagelos Fradelos, Paraskevi Theofilou, Maria Lavdaniti, Sofia Zyga. Fatigue in Arthritis: A Multidimensional Phenomenon with Impact on Quality of Life, Fatigue and Quality of Life in Arthritis. GeNeDis 2016; volum 987, pp 243-256.

4. Jonna K., van Vulpena, Petra H.M. Peetersab, Miranda J., Velthuisc Elskenvan 
der Walld, Anne M.Maya. Effects of physical exercise during adjuvant breast cancer treatment on physical and psychosocial dimensions of cancer-related fatigue: A meta-analysis. Maturitas 2016, Volume 85, Pages 104-111.

5. Micol Artom, Rona Moss-Morris, Fergus Caskey, Joseph Chilcot. Fatigue in advanced kidney disease. Kidney International Journal. 2015; Volume 86, Issue 3, Pages 497-505.

6. Moylan, J. S., and Reid, M. B. (2007). Oxidative stress, chronic disease, and muscle wasting. Muscle Nerve. 2007; volume 35, Pages 411-429. doi: 10.1002/mus.20743.

7. Kennedy G, et al. Oxidative stress levels are raised in chronic fatigue syndrome and are associated with clinical symptoms. Free RadicBiol Med. 2005;39(5):584-9.

8. Maes M. Inflammatory and oxidative and nitrosative stress pathways underpinning chronic fatigue, somatization and psychosomatic symptoms. Curr Opin Psychiatry. 2009;22(1):75-83.

9. Azmeh Shahid, Jianhua Shenac, and Colin M.Shapiroa. Measurements of sleepiness and fatigue, Journal of Psychosomatic Research 2010; Volume 69, Issue 1, Pages 81-89.

10. Masoumeh Bagheri-Nesami, Seyed Afshin Shorofi, Attieh Nikkhah, Fatemeh Espahbodi, Fahimeh-SadatGhaderi Koolaee. The effects of aromatherapy with lavender essential oil on fatigue levels in haemodialysis patients: A randomized clinical trial.Complementary Therapies in Clinical Practice 2016; Volume 22, , Pages 33-37.

11. Shahdadi, H., Hodki, R.M., Abadi, A.A., Sheikh, A., Moghadasi, A. The effect of slow stroke backmassageon fatiguein patients undergoing hemodialysis: A randomized clinical trial. International Journal of Pharmacy and Technology 2016; Volume 8, Issue 3, September 2016, Pages 16016-16023.

12. Aaron B. Holley, MD. The Evaluation and Management of Fatigue. Medscap critical care, 2015.

13. Bossola, M., Vulpio, C., and Tazza, L. Fatigue in chronic dialysis patients. Semin Dial. 2011; 24: 550-555

14. Brass EP, Adler S, Sietsema KE, Hiatt WR, Orlando AM, Amato A; Intravenous Lcarnitine increases plasma carnitine, reduces fatigue, and may preserve exercise capacity in hemodialysis patients. Am J Kidney Dis 37:1018-1028, 2001.

15. Singer RF: Vitamin C supplementation in kidney failure: effect on uraemic symptoms. Nephrol Dial Transplant 26:614620, 2011

16. Salehi M, Sohrabi Z, Ekramzadeh M, Fallahzadeh MK, Ayatollahi M, Geramizadeh B, et al. Selenium supplementation improves the nutritional status of hemodialysis patients: a randomized, double-blind, placebocontrolled trial. Nephrol Dial Transplant. 2013; 28(3) : 716 -23

17. Sedighi O, Zargari M, Varshi G. Effect of Selenium Supplementation on Glutathione Peroxidase Enzyme Activity in Patients With Chronic Kidney Disease: A Randomized Clinical Trial, Nephro-Urol Mon. 2014 ; 6(3):e17945.

18. Knight, T.R.; Fariss, M.W.; Farhood, A. and Jaeschke, H. Role of lipid peroxidation as a mechanism of liver injury after acetaminophen overdose in mice. Toxicol. Sci. 2003; 76(1):229-236.

19. Wollin, S. D. and Jones, P. J. H. a-Lipoic Acid and Cardiovascular Disease. J. Nutr. 2003; 133(11): 3327-3330. 